DE DE GRUYTER OPEN $\overline{\mathrm{G}}$

Mary M. Piecewicz

Clark University

Gang LuO

Fitchburg State University
Journal of Intercultural Management

Vol. 6, No. 1, January 2014, pp. 27-45

DOI 10.2478/joim-2014-0003

\title{
Applying the Communication Perspective for Global Compliance Training
}

\begin{abstract}
With the advancement of telecommunication technologies and strategic outsourcing, globalized business management has become a necessity to establish and maintain operations in lucrative emerging markets. With the world's largest market, talent pool and labor force, China has emerged as an inevitable destination for many multinationals. However, China's unique political system, socio-economical settings and cultural environment poses the great challenges to global businesses. One of the greatest hurdles faced by multinationals is effectively transporting Western business conduct and ethics. Embedding Western ethical compliance into operations based on China's powerful and highly influential cultural practice - Guanxi Networking - is proving to be the ultimate challenge.

To address this intercultural disconnect, this research paper applies the principles of the communication perspective, derived from the theories and practice of the Coordinated Management of Meaning (CMM). Our proposal suggests an ethics compliance training based on a framework of trust and collaboration - a new approach to tackle the dilemma between the Western ethics and the cultural norms driven by guanxi networking. This research based proposal explores the application of the communication perspective in a holistic method.
\end{abstract}

Key-words: anti-corruption, communication perspective, Coordinated Management of Meaning, ethics, guanxi networking, 


\section{Ethics Training Approach}

Our hypothesis is that the case study model for corporate ethics and anticorruption compliance training should be based on three fundamental guiding principles:

- Bridging the Culture Gap (Awareness of Guanxi Networking)

- Building a Collaborative Perspective (Communication Perspective)

- Breaking down the Cultural Barriers (Changing Attitudes and Behaviors)

If the strategy of the multinational is to embed and enforce the notion of Western ethics, then the strategy must align with the cultural attitudes of nonWestern employees. Applying the communication collaborative perspective of building a "better story" - one of compliance and cultural sensitivity - is a mechanism to ensure success. Through collaborative communication - gaps in cultural understanding and awareness can be addressed. With increased awareness, cultural barriers give way to changes in attitudes and behaviors. Once these foundational principles become operationalized within a training program, a corporation can then move forward to implement their compliance program. To ignore the importance of the collaborative foundation and to immediately start conducting ethics training based solely on Western legal considerations is a prescription for failure.

Most critical is that corporate training developers (steeped in Western culture) need to have a baseline understanding of two critical concepts: (1) role of culture and (2) role of communication in changing attitudes and behaviors.

Through exposure to the concept of guanxi and a fundamental understanding of the Communication Perspective, a comprehensive ethics and anti-corruption training program can be developed. Incorporating the cultural aspects, as well the goal to achieve a "better social world", results in a holistic program that has far reaching impacts beyond strict compliance to the "law".

\section{Case Study Methodology}

Stories, including myths, legends, and folk tales have been used to pass on wisdom, knowledge, and culture for thousands of years (McLellan \& Reamy cited online 14 July 2003,www.techhead.com). Vignettes, described as "short stories about hypothetical characters in specified circumstances, to whose situation the participant is invited to respond," (Finch 1987, pp.105-114) and "short scenarios in written or pictorial form, intended to elicit responses to typical scenarios," (Hill 1997, pp. 171-183) are ideal for training . And the use of stories is critical to the concept of the communication perspective. Case studies are a form of short scenarios and are widely valued because they simulate a real word context. (Wenger 2000,pp. 205-224). This is the rationale for case-based ethics and anti-corruption training. 
Corporate employees, participating in the case study analysis and problem resolution, apply theory to actual everyday business practice. In other words, they learn by doing. (Erskine, J.A., Leenders, M.R. and Mauffette-Leenders, 1998).

Utilizing a cultural based case study as the foundation for ethics and anticorruption compliance training is aligned with the communication perspective. A case-based vignette with real life situations, allows both the employee and the corporate trainer to dialogue and discuss social actions and how these actions are perceived from different cultural frameworks. Scenario specifics take the discussion from the realm of concepts and constructs to practical business application.

Most critical for training developers and instructors is the understanding of the art of guanxi networking from a cultural perspective - not a business based perspective. A short overview of the Chinese "art of networking" is required as part of the training development. In addition, a baseline understanding of the Communication Perspective is critical for ensuring long term success in developing a training module geared to intellectual understanding and compliance as well as operationalized changes in attitudes and behaviors.

\section{The Art of Relationships}

Before embarking on developing a corporate training curriculum around ethics and anti-corruption, training developers and instructors need to be able to answer the question, "What is guan-xi"? From the Chinese perspective, guanxi means personal connections and relationships that are mutually beneficial to both parties. It contains two Chinese characters: "guan" which indicates concerning, relating and caring; "xi" suggesting links, ties, and connections. "Guanxi networking" refers to the common practice of identifying, establishing, maintaining and leveraging guanxi networks. It can be considered the Chinese "art of relationships".

Guanxi networking operates in a fashion similar to networking in Western culture. In a business setting, typical activities performed by the Chinese managers, may very well occur in the United States, such as a paid training trip to a vacation resort, or closing a deal on a golf course. However, as a socially constructed communication process, the two cultural approaches differ in meaning and action. Specifically, Guanxi networking and Western networking diverge on the following aspects:

1. Cultural origin - role of trust

2. Development and type of trust established

3. Social and cultural impact

4. Ethical consequences 


\section{The Role of Trust}

Hofstede's cultural dimensions theory proposes that Chinese culture is characterized by a high level of collectivism (Hofstede 2001, pp. 209-216). A closer examination (Lai 1995; Lang 1946; Yang 1988 cited in Chua, Morris, and Ingram 2009, p. 491 and Neuliep 2012, pp. 69-71) further reveals the Chinese collectivity tends to center on families and closely-knit groups. The origin can be traced back to Confucianism's long-standing ethical teaching. Confucianism is the source of many core Chinese cultural traditions, including a strong emphasis on loyalty, filial piety and family value (Fingarette 1972 pp. 40-55). This family oriented ethic provides the cultural context and the moral ground for constructing guan-xi networks. Moreover, the development of any meaningful relationships entails the element of trust. Social researchers (Chua, Morris and Ingram 2009, p. 491) propose that the trust cultivated from familial collectivism is based more on emotion than on reason (affect-based vs. cognition-based trust). Family members share resources. An individual sacrifices personal needs and does his/her part to serve the common goals of the family. In contrast, Western culture is heavily influenced by Cartesian individual-society dichotomy (Cronen, Chen and Pearce 1988, p. 73). In this case, networking is established on cognition-based trust that is rooted in a rational assessment of the authority's (government, corporation) trustworthiness.

Living in a collectivism society, the Chinese view people differently as "ingroup" and "out-group" members. Chinese have a much higher confidence in "in-group" members than "out-group" members. It is important when multinationals are developing ethics and anticorruption training, that they employ a member of the local Chinese subsidiary as a subject matter expert. Time must be accounted for the Chinese contributor to develop a sense of trust with the corporate training group. But the passing of time, and the development of a sense of collectivity, the "out-group members" (multinationals) can be considered "in-group members". This inclusion of the Chinese perspective based on trust will ensure a more robust and meaningful training program.

\section{Social and Cultural Impact}

Ethical origins and the type of trust involved have a visible impact on networking behaviors. Among Chinese managers, the construction of a network of professional relationships evolves as a logical extension of their family relations. Guanxi networks form a hierarchy composed of circles and the degree of affect-based trust decreases when the social interactions move away from the family circle. The most ideal business partners within the guanxi network is the person managing multiple trusted social links: a family member (the blood tie), with whom one gets along well (the friendship tie), and also a potential career collaborator (the professional tie). 
American managers, by comparison are less inclined to include family members and friends in their business networks. Research indicates adherence to the Protestant work ethic interprets the involvement of personal relationships and emotional concerns in commerce as highly unprofessional. Such actions violate Western norms regarding professionalism and friendship (Chua, Morris and Ingram 2009, p. 492).

Guanxi is also a way of life woven into the fabric of the Chinese society. In order to advance personal and institutional agendas in China, the practice of guanxi is a necessity. Guanxi is widely recognized as a wellspring of resources for many endeavors ranging from acquiring better family medical care, securing contracts, to job security and promotions.

In contrast, Western ethics and norms dictate that personal connections and networking are largely discouraged. Western business strategy is two dimensional: (1) striving to seek compliance with the rule of law; and (2) executing business operations within the law (Lane and Hoffman, 2012, p. 28). As a result, the conventional Western business wisdom is not effective in the Chinese market. The complex and intertwined Chinese relationship network renders everything non-linear and multidimensional. Without following the hidden, under-the-table rule of guanxi that governs the society (Liu 2012), it is difficult to predict the outcome of investment and business efforts (Lane and Hoffman 2012, pp. 28-29). In characteristic Western business operations, the relationship with clients follows as the by-product of an amicable transaction. However, the rule of Guanxi requires reversing the process, and places relationship in the foremost position of business transactions.

\section{Ethical Consequences}

Ethics are heavily influenced by cultural norms within a specific cultural tradition. Networking activities endorsed by the ethical standards in one culture may not be accepted in another. Two social systems can be so divided politically and culturally, that they are considered to be incommensurable. Yet they may be comparable (Cronen, Chen and Pearce 1988, p. 70). It is neither logical nor sensible to draw conclusions about a certain behavior in one culture based on ethics in another. Essentially, they are two different paradigms. For example, judging the legitimacy of a football player's action according to the rules of soccer is downright ridiculous.

\section{Relationship Resources}

Basically, there are three players in the process of social interaction and relationship building: the government, organizations and individuals. These entities form a unique triangular relationship. Each relationship is governed and regulated by laws, ethics and norms. From an individual's perspective, three 
types of relationships may occur: (1) the relationship between the individual and the government; (2) between the individual and organizations; and (3) the relationships constructed among individuals. When individuals strive to live a better life in one social system, individuals consequently use these relationships as culturally based resources. An individual may acquire resources from the government, the organizations, and also from other individuals.

Every relationship in the individual participates is contractual. Between individuals and the government, there is the concept of social contract. The individual agrees to follow laws and regulations in exchange for protection, social security and other resources. Between individuals, the relationship they enter may form a social contract. Each individual becomes a means for the attainment of resources of others. In order to protect individuals from being overused and abused, certain cultural norms and ethics are formed (MacIntyre 1994, p. 223).

From culture to culture, the three contractual means for individuals to obtain resources are not socially-constructed equally. Comparing the social system between the US and China, for example, relationships based on social contract and social capital offers more reliable resources in the United States as opposed to China. The outcomes of social actions in the US are more predictable based on the law. The practice of following the laws evolves into a critical aspect of the cultural norm, as well as an important part of Western ethics. The interpersonal relationships become an optional source. Because the influence of the legal tradition is strong, even issues raised from interpersonal relationships are often remanded to law. In the Western system, individuals depend on society for resources and protection by way of the legal system.

In China, historically, the concept of social contract is largely unexpressed. Because the political system tends to be elitism, interpersonal relationships serve as a nobler indicator of the outcomes of social behaviors. Individuals resort to interpersonal relationships for resources. This process begins with the family. Individuals naturally carry their familial collectivism-based relationship model into their professional lives as well. Principles governing interpersonal relationships are well established, As a result, these relationships become respected, powerful and prevalent cultural norms. They are the ethics by which people abide. In short, the cultural norms of guanxi.

These reliable relationship sources provide the individuals not only the material resources to live a good life, but also the psychological and spiritual values recognized in the culture. These psychological values include virtues and merits that grant social status, acknowledgement, as well as the satisfaction of self-actualization. Furthermore, the spiritual resources provided and their relationship sources are in a relation of reflexivity. The definition of "a good 
life" varies historically and culturally as well. Between Chinese and Western cultural traditions, virtues sustained by following laws and rules can be quite different from the values endorsed by the cultural norms of guanxi.

Take the concept of freedom for example. As one of the most deeply held American values, freedom can be viewed as a constant struggle between individualism and collectivism. Because interpersonal relationships are an optional resource, the individualistic aspects of the concept are better supported in the American society. Freedom is often interpreted as staying alone from others and not accepting other people's values, ideas and lifestyles (Bellah, Madsen, Sullivan, Swidler and Tipton 1985, p. 23). Consequently, associated qualities, such as being different, unique and competitive, are regarded as socially approved personal traits as long as they are exercised within the scope of the laws and other rules. However, in the cultural tradition that emphasizes on interpersonal relationships and familial growth, collectivism carries more advantages than individualism. In a collective culture like China, being different or competitive is likely to be disapproved by the cultural norms.

\section{The Impact of Law and Culture}

Adopted by Transparency International, corruption is commonly defined as the abuse of entrusted power for private gain. However, this definition leaves much to discussion, particularly when it is placed against a different social and cultural context. Some scholars even suggest that this concept of corruption comes exclusively from the globalization of the Western culture. It does not fit or correlate in many non-Western social value constructs.

\section{The Variance in the Concept of Corruption}

The inconsistent ethical standards among cultures lead to variations of the concept of corruption. In order to understand a specific interpretation on the concept of corruption, it is important to understand its' cultural context. For example, from the cultural perspective of Americans, US companies outsourcing labor-intensive jobs to China, taking advantage of the vast and inexpensive labor market to minimize labor costs can be regarded as a form of exploitation and victimization of the local population. Outsourcing has been criticized by many Americans as an unethical strategy. However, the Chinese culture which emphasizes collectivism and family economic needs, as opposed to the absolute protection of the individuals, may tolerate and accept such a strategy as a social reality. Because cultural traditions and interpretation contribute much to an individual's judgment on what constitutes corruption, the understanding of the concept can vary dramatically from person to person as it varies dramatically from culture to culture.

Corporate corruption takes on various forms, such as bribery, fraud, insider trading, favoritism, cronyism and nepotism. Many of these behaviors, although 
considerably unethical, are not necessarily prohibited and prosecuted by law. For example, in the United States, bribery has only been prohibited by law since Foreign Corrupt Practices Act (FCPA) was passed by Congress in 1977. Prior to the passing of the FCPA legal statute, bribery was prevalent within the US private sector to secure foreign contracts. It was not considered an unethical business practice before 1977 (PBS Frontline/World 2009). However, due to its legal definition, bribery has been deemed unethical and illegal from the US (Western) perspective.

Conversely, in China, although many forms of bribery have been outlawed by its tightened 2011 criminal law revision, many of the same forms of bribery are still perfectly acceptable under well-established culture norms. Guanxi networking is routinely carried out by business practitioners and not to be regarded as unethical. The culture force has such a strong hold over people's behaviors and moral judgment, even when their behaviors may be punishable by law.

\section{Corruption as an Action}

As one of the major sources of cultural conflict, the divided understanding of the concept of corruption is more expressed in action (Chetro-Szivos 2006, p. 38), instead of in meaning. Take gift-giving for instance; both the state legal system and the predominant social values in China uphold the similar ethics standards towards corruption as the Western ethical tradition. The common Western definition of corruption is also widely accepted by the general population in China. Looking at the meaning alone may not reveal many differences between the two cultural systems - after all, giving gifts as a method of maintaining relationship is widely applied in the U.S. as well. However, the drastically different cultural practice displays the clashing understanding in the concept of corruption.

\section{Moral Decision Making}

It is particularly meaningful to distinguish ethics from morals in the discussion of corruption when guanxi networking is concerned. Globalization has highlighted the clash between the traditional Chinese thinking and the Western ideology. As a result, today there are various ethical standards coexisting in the society. Long-standing cultural traditions exercise powerful influences over people's thinking and actions. As a consequence, there is a constant battle between the officially endorsed ethics upheld by laws, authorities and mainstream social values, and the ethical standards heavily influenced by the culture. The act of corruption is not simply a problem of law enforcement; fundamentally, it is a matter of morality (Zalta 2008). It is up to the individual to choose ethics and make their own moral decisions. 
In China, although the dominant ethical attitude towards corruption, presented by legislation and the mainstream social values, are largely in line with Western ethical standards, the widely practiced guanxi networking clearly demonstrates a different understanding.

\section{CMM and Anti-Corruption Compliance Training}

Traditional Western management strategies, government legislation and corporate policies tend to treat anti-corruption compliance as a straight forward approach. The standard compliance training development process often is a linear process:

1. Identify the finite set of critical elements for compliance, (code of conduct, regulations, internal procedures, monitoring, and employee training);

2. Establish and implement key internal control points to ensure control to compliance;

3. Evaluate the collected results and adjust the system to complete the management cycle.

Ultimately, what is lost in this traditional approach is the acknowledgement and resolution of the clash between Western ethics and the powerfully influential cultural force of guanxi networking. Complexity and uncertainty in cultural conflicts resemble more of a "mystery" than a well-defined corporate process of "plan-do-check act" (Deming, 1986). Moreover, the goal of corporate ethics and anti-corruption compliance is to achieve the absence of corrupt conduct. There is no doubt that unraveling the cultural component of conflicting ethical views on corruption is a considerable undertaking. It requires more than just an understanding of FCPA regulations, writing a corporate code of conduct and developing traditional anti-corruption employee training sessions. Today's globalized business environment needs a paradigm shift both in thought and action.

\section{Power of Coordinated Management of Meaning}

Developed by Barnett Pearce and Vernon Cronen, the Coordinated Management of Meaning (CMM) has long been recognized as one of the major methods of managing meanings within our conversations. (Pearce 2004, p. 37). With a strong focus on building a better social world through a communication perspective, the CMM theory is particularly beneficial to reconstructing and transforming conflicts among different cultural traditions within a corporate setting for the following reasons:

First, as a prominent theory in culture and communication (Hall 1992, p. 30), CMM seeks to answer the question as to how individuals can overcome cultural differences and barriers. The challenge is to find ways of acting together that create a social world not based on culture warfare, but based on 
a collaborative framework. A framework from which individuals and groups can find the comfort and stability of their traditions without denying the same privilege to those in other traditions (Pearce 2004, p. 49). Second, the CMM theory offers new concepts, tools and most importantly, a new perspective to rethink traditional training approaches. And finally, CMM is both critical and practical as its ultimate aim is to bring about social changes.

The communication perspective recognizes communication as inherent to all social activities. Communication is the primary social process that creates and maintains social and cultural conflicts. It is also the social process capable of breaking down or transforming cultural barriers. Characteristics embedded in the communication process can provide individuals with a roadmap for formulating new and more constructive communication methods (Pearce 2004, p. 37-39).

The communication perspective regards human communication as both idiosyncratic and social, as opposed to the Cartesian tradition of the subjectiveobjective and the individual-society dichotomy (Cronen, Chen and Pearce 1988, p. 72). In the era of globalization and social media, traditional individualistic thinking and competitive practice patterns do not help when individuals with very different beliefs, values, and lifestyles, are forced to interact with each other. The result is that individuals are faced with the alternative of either clashing in conflict or hesitatingly accommodating each other's differences (Berger 2001 cited in Pearce 2004, p. 36).

\section{Relationships of Interdependency and Reflexivity}

The communication perspective takes the stance that the relationship between the meaning and the action involved in communication are reflexive - they are interrelated and interdependent (coherence). Action is directed by meaning, while meaning is sustained and/or altered through action. This principle can also be applied to different cultural traditions coming into communication. Although cultural conflicts are destined to occur when the meaning and action system within one culture presents challenges and risks to the opposing cultural system, the two cultural traditions form an interdependent and reflexive relationship.

Communication can also be viewed as an interconnected joint action (coordination). Cultural conflicts are not a static state between two cultures; they are meanings and actions created collectively through communication and likely to change in the future (Chetro-Szivos 2006, p. 34).

\section{Mindfulness}

The Communication Perspective requires participants to be aware of what is created together in the moment of communication, as well as the social, 
cultural and organizational context (Pearce 2007, p. 26). It is within context that communication comes to life. Characteristics of the Communication Perspective provide the rationale for training developers, instructors, managers and employees to take a holistic view:

1. Context: Meaning cannot be taken out of its social, historical and cultural context

2. Interpretation: communication is subject to multiple levels of interpretation

3. Imperfectness: all human communication is inherently imperfect and incomplete

4. Afterlife: communication as a joint action has an "afterlife"

5. Complexity (mystery): complexity of human stories, interpretations and outcomes

\section{Stories}

Including stories lived, stories untold, stories unknown, stories unheard, stories telling (Pearce 2007, pp. 210-213); stories are powerful manifestation of values, norms, worldviews, speech codes and interpretation. Cultural traits are preserved and passed on from generation to generation through storytelling. Being mindful of people's stories invokes the realization that all stories, including one's own, are unfinished, incomplete, biased and inconsistent. Individual tend treat their own stories as "local" and the stories differ from theirs as "valid" (Pearce 2004, p. 50). Also, stories are not just cultural memoirs set in stone; they are readily expanded, modified, and manipulated. New stories are constantly being created and emerging. By invoking the process of storytelling as part of the anti-corruption training, participants are exposed and made aware of cultural values and norms of others.

\section{Patterns}

Communication is a magnificent creature of habit. People who share the similar traits may tend to join together to form a circle or organizational behavior patterns. Not surprisingly, cultural norms, biases, mindsets and thinking habits all take on the form of patterns. The cultural rituals of Guanxi networking, performed by the local Chinese managers are evidently a pattern of communication. Mindful managers may want to be cautious about certain patterns, such as dualism, stereotyping and isolated individualistic point of views. Instead, cultivating constructive communication patterns inviting coordination, corporation and collaboration plays a crucial role in transforming and reconstructing cultural differences.

\section{Critical Moments}

Critical moments shape the world, impact lives and often determine the outcome of an individual's endeavors. Since culture clashes happen in global 
organizations, a manager's ability to be aware of these tipping points and ability to act wisely in these moments (Pearce 2007, p. 1) are particularly valuable. Acting wisely calls for a comprehensive consideration of the possible stories, contexts, interpretations and outcomes, as well as staying away from potentially detrimental communication patterns. In order to develop or strengthen the capability of making prudent judgments, this analytical critical thinking practice may also be conducted consistently after the occurrence of the events, and then applied as lessons learned to future events.

\section{The Holistic View}

An organization is an organic entity. It is all about the relationship and communication among the people within the organization. The communication perspective prompts the individual not only to be aware of different views, values, norms, but also to understand their connections, relationships and interdependency to function as a whole within the corporate culture setting. It is through the communication perspective that participants take into account people's stories of the past, as well as their potential changes for the future.

The holistic view can be applied to practical management tasks. In the formulation of an anti-corruption compliance training strategy, three possibilities can be considered:

1. Change the rules of the entire system, which reorganizes the system's resources;

2. Rally all related stakeholders, even competitors, to form a collaborative effort;

3. Motivate separated management aspects to work in concert in an altered system to achieve multiple positive outcomes.

\section{Application of the Communication Perspective}

Aside from new concepts and thinking methods, as a cultural product, the communication perspective employs a set of new tools in analyzing and managing the culture dilemma. The communication perspective holds that even when two cultural systems are incommensurable, such as Western and Chinese ethics system, they are still comparable. But the means of comparison has to be created (Cronen, Chen and Pearce 1988, pp. 69-70). The communication perspective believes that lived experience, stories carried in conversations, for example, forms the foundation of cultural comparison.

The communication perspective focused on actions within multiple levels of embedded contexts from highly structured cultural episodes with rituals, roles and prescribed behaviors (Pearce 2004, pp. 39-40). These episodes are conducive to answering questions, such as "what did they do and why did they do it?" These questions indicate that the primary social process of communication is also a 
decision-making struggle: what meaning to construct and what actions to take. As powerful contextual cultural forces are pulling individuals simultaneously from all directions (Pearce 2007, p. 7), CMM's analytical methods of contexts, patterns and episodes are particularly helpful for managers to make decisions at critical moments.

By constructing a culturally based case study, there are many episodes that can be described with rich and colorful cultural contexts. By framing the episodes against the Western notion of ethics, training developers can pose thought provoking discussions for class room discussions. The case scenario provides a forum where the culture context plays a critical role in the Chinese mangers' decision-making process. The communication perspective recognizes it (guanxi) as the culture's contextual and prefigurative forces. This has the effect of making the local Chinese employees explore the notions of what they feel they "ought to do", "must not do", "should do" or "may do" within a multinational business environment based on Western legal constructs.

Additionally, the communication perspective is both critical and practical, aiming to bring social changes. When cultural conflicts occur between two incommensurate social worlds, the cultural resources can differ so much that neither is able to provide a sufficient guide for actions to resolve the conflict. The communication perspective has the critical edge (Pearce 2004, pp. 43-45) to reveal stories, issues and options that participants within the conflict may be unaware by reconstructing the communication as a sequence of actions from both sides.

Last, contemporary management theories corroborate the principles of the communication perspective. In a management setting, its emphasis on human connections and the holistic view resonates well with the systems thinking, which regards the system as parts connected and joined together as a whole by a web of relationships (Banathy 1997); In addition, the learning organization theory, which argues that only organizations being able to adapt quickly and effectively will be able to excel in their field or market (Senge 1990, pp. 13-15) indirectly supports the principles of CMM.

\section{Cultural Traditions}

By using a culturally based case scenario in anti-corruption training, it is important for training developers and instructors to recognize and acknowledge the critical role that culture plays. Although the conflict appears to be between the anti-corruption legislation and a prevalent local business practice in China, essentially, the conflict represents a distinct view in understanding ethics and what really constitutes corruption from Western ethical standards and a deeprooted eastern relationship building perspective. The case study presents the 
divide between two incommensurable cultural traditions set against a global commercial background.

However, it must be demonstrated in the training that the two cultural systems are not always in a clear-cut opposing position. Although the wide-spread practice of guanxi networking exhibits a drastically different understanding of the concept of corruption from the Western ethical tradition, legislation and law enforcement in China support a set of similar ethical standards. Even though Western code of ethics is the driving cultural force behind the business conducts in the U.S., within the private sector, it is not uncommon to see client relations are maintained through personal kickbacks or gift-giving. The similarities between the two cultures suggest that even they are incommensurable, they are still comparable.

\section{Understanding and Appreciating Cultural Differences}

When in contact with another culture, a practical and effective strategy proposed by the communication perspective suggests that training modules demonstrate first the attempt to understand, and then even try to appreciate the cultural differences.

This method invites training participants to consider a few changes in attitude and mindset when developing and delivering anti-corruption training: 1. Demonstrate a non-judgmental position. "My way or the highway" attitude only widens the cultural gap.

2. Encourage the competency to think beyond one's own cultural tradition; even question the worldview one takes for granted.

3. Develop the awareness of the existence of many other ethical standards and acknowledge their validity as well as one's own

The communication perspective is particularly conducive to helping training participants understand that, in an attempt to reconstruct cultural differences, the pluralistic view on ethics and corruption provides the precursor to a collaborative framework.

By applying the communication perspective in anti-corruption training, instructors need to take a critical stance to acknowledge and value participants. They internalize (Berger and Luckmann 1966 cited in Burr 1995, p. 10), and hold that cultural tradition and its manifestations - values, norms, ethics, morals and worldview (Hall 2005, pp. 30-32) are neither given by our cultural surroundings, nor a product of our biological traits. Instead, culture is a set of joint social actions created and developed through the primary social process of human communication (Burr 1995, p. 4); Cultural traditions continue to evolve as long as our social dependency remains. A set of universal ethical guidelines does not exist, instead, all existing ethical standards are acknowledged. They 
are equally valid within the tradition where they were socially constructed (Gergen \& Gergen 2004, p. 18).

\section{Considerations for Anti-Corruption Training}

When multinationals undertake establishing a global anti-corruption program several key components are required according to US based Corporate Executive Board (2010):

- Program Structure, Design, and Oversight

- Legal and Compliance Risk Management

- Policies, Standards, and Procedures

- Training

- Communications

- Allegation Reporting and Investigations

- Discipline and Incentives

- Program Measurement and Monitoring

In large global firms, training design and development are largely seen as a process step needed to address a business objective. Efficacy of the training is usually evaluated through learner assessments (Clark, 2012). Most corporations utilize the Instructional System Design (ISD) model or a similar paradigm for training development. These design approaches are geared toward meeting internal metrics based on the corporate strategies and objectives. There is very little acknowledgement of the impact and influence of the larger cultural environment experienced by the training participants. Normally, this is not an issue. However, when developing a training module that addresses Anti-Corruption in a non-Western country-culture plays a huge role. For anticorruption training, the true success of employee training is demonstrated over time through compliant actions, attitudes and behaviors - not in assessment tests or metrics.

The prescription for ensuring a robust anti-corruption training program is to include the following critical success factors as part of the ISD phases of the training program:

- All training developers and instructors undergo instruction in the cultural aspects of ethics from a Western as well as a Chinese world view. This instruction includes the discussion of guanxi networking and how the role of law is central to the Western perspective of commerce.

- The development of case study based on cultural practices by local trainers. Having the case study developed by locals and not by the corporate training department can ensure that cultural reality is reflected in the case study.

- The deployment of the training module should be facilitated by local trainers who are familiar with local communication context, speech code, 
interpretation, and complexity. Dialogue and discussion around complex ethical situations are more robust when led by local trainers. It has been observed that participants are more likely to engage with others who have the same cultural background. Along with the local trainers, it is highly recommended that high level corporate managers also attend and participate. Providing executive (and Western insights) to the analysis of the case study presents a perfect opportunity for participants to view the intersection of world views around a genuine business issue.

- Active engagement and storytelling by the training participants brings the notion of CMM storytelling to fruition. It is important to build into the training an opportunity for participants to share their insights, issues and concerns around the notion of anti-corruption with the training facilitators. This dialogue breaks down the misunderstanding and confusion around compliance in a corporate culture that in many ways is in direct conflict the larger local culture. The story telling component becomes the stepping stone to building a better social place - a compliant commercial enterprise.

- A reinforcement training strategy is an essential component for the overall anti-corruption training. Couching, management follow-up discussions and informal group discussions on new insights gained help reinforce new ideas and concepts. Reinforcement provides structured opportunities for employees to practice skills and knowledge learned through dialogue and the ability to apply new insights to their day to day job. In addition, ongoing communication around the concepts of anti-corruption allows for new information to be brought forth. Changes in global legal rulings around bribery and anti-corruption can be shared real time. Adaptation to global trends on transparency and compliance becomes embedded in the corporate entity, rather than a standalone once a year training exercise (Moran 2005, p.4).

\section{Conclusions}

Cultural conflict is one of the essential elements of globalization and is acknowledged as one of the significant business risks for multinationals operating in China. Distinct attitude and practices influenced by local cultural norms (Language \& Culture Worldwide 2010 cite www.LangauceAndCulture. com) towards what constitutes corruption, such as the guanxi networking, has been identified as the major barrier for ethical compliance worldwide. Moving from competition to collaboration results in approaches that are focused more on commonalities than differences. This shift will allow a company to build more competencies to address its cultural conflict challenges (Brown 2012, pp. 15-17). 
Embedded awareness on the role of culture and communication with the corporate ethics and anti-corruption training can lead to much higher level of compliance based on attitude and behavioral changes. Keeping the notion of compliance forefront on a daily basis through stories, dialogue and discussion ensures a great success rate than one time training events with standard assessment tests.

\section{Bibliography}

Banathy, B. H. (1997). A Taste of Systemics. Why a system view. Retrieved from http:// www.newciv.org/ISSS_Primer/asem04bb.html

Bastiaan, W. (2009, June 23). Chinese credit management: any progress made? Retrieved from Credit-to-Cash Advisor: http://www.credit-to-cash-advisor.com/ articles/creditmanagement/chinesecreditmanagement-1

Bellah, R. N., Madsen, R., Sullivan, W. M., Swidler, A., \& Tipton, S. M. (1985). Habits of the Heart. University of California Press.

Berger, P. L. (2001). Forward. In R. C. Neville (Ed.), The Human Condition (pp. xi-xiv). Albany: State University of New York Press.

Berger, P., \& Luckmann, T. (1966). The social construction of reality. Anchor Books.

Brown, M. (2012). A manual for civic arguments: An ethical approach to controversial issues. Submitted for Publication.

Buderi, R., \& Huang, G. T. (2006). Guanxi (the art of relationships): Microsoft, China, and Bill Gates' plan to win the road ahead. Simon \& Schuster.

Burr, V. (1995). An introduction to social constructionism. Routledge.

Chetro-Szivos, J. (2006). Talking Acadian: Communication, work, and culture. New York: YBK Publishers, Inc.

Chua, R. Y., Morris, M. W., \& Ingram, P. (2009). Guanxi vs. networking: Distinctive configurations of affect- and cognition-based trust in the networks of Chinese vs. American managers. Journal of International Business Studies, 490-508.

Cronen, V. E., Chen, V., \& Pearce, W. B. (n.d.). The coordinated management of meaning in intercultural communication: A critical theory in the pragmatic tradition. In Y. Kim, \& W. Gudykundst (Eds.), Theories in Intercultural Communication (pp. 66-98). Newbury Park: Sage.

Diffen. Ethics vs. morals. Retrieved from diffen: http://www.diffen.com/difference/ Ethics_vs_Morals

Erskine, J.A., Leenders, M.R. and Mauffette-Leenders, L.A. Teaching with cases, Ivey Publishing, London. 1998.

Finch, J. "The Vignette Technique in Survey Research". Sociology, vol. 21, pp. 105-114, 1987.

Fingarette, H. (1972). Confucius: The secular as sacred. New York: Harper.

Gergen, K., \& Gergen, M. (2004). Social construction: Entering the dialogue. Taos 
Institute Publications.

Gladwell, M. (2007, January). Open secrets. The New Yorker.

Hall, B. (1992). Theories of culture and communication. Communication Theory, 2(1), pp. 50-70. doi:10.1111/j.1468-2885.1992.tb00028.x

Hall, B. (2005). Among cultures: The challenge of communication. ThomsonWadsworth.

Hennessy, B. (Ed.). The art of guanxi. Retrieved from China Australia Consult: http:// www.china-consult.com.au/2010/09/21/the-art-of-guanxi-2/

Henry, R. (2013, July 17). Jimmy Carter: Unchecked political contributions are 'legal bribery'. Retrieved from Huffington Post: http://www.huffingtonpost. com/2013/07/17/jimmy-carter-bribery_n_3611882.html

Hill, M. "Research review: participatory research with children, child and family". Social Work, vol.2, pp. 171-183, 1997.

Hofstede, G. (2001). Culture's consequences: Comparing values, behaviors, institutions and organizations across nations. Sage Publishing. Retrieved from The Hofstede Centre.

Hofstede, G. (1993) Cultural constraints in management theories. Academy of Management Executive, 1993, Vol.1, No1. p. 81.

Holzer, J., \& Raice, S. (2011, March 19). IBM settles bribery charges. Retrieved from The Wall Street Journal Website: http://online.wsj.com/article/SB10001424052748 704608504576208634150691292.html

Lai, G. (1995). Work and family roles and psychological well-being in urban China. Journal of Health and Social Behavior, 36 (1): 11-37.

Lane, S., \& Hoffmann, W. J. (2012, September-November). Does the Chinese practice of Guanxi lead to corruption in business? Compliance Insider Magazine. Retrieved from Ethic Intelligence.

Lang, O. (1946). Chinese family and society. New Haven, CT: Yale University Press.

Language \& Culture Worldwide. (2010). 2009 survey report: global ethics \& compliance programs. Retrieved from Language and Culture Web site: www. LanguageAndCulture.com

Liu, M. (2012, August 20). Graft or Guanxi? A bribery probe casts a spotlight on an ancient Chinese term. Retrieved from The Daily Beast: http://www.thedailybeast. com/newsweek/2012/08/19/graft-or-guanxi.html

MacIntyre, A. (1989). Whose justice? Whose rationality? Notre Dame, Indiana: University of Notre Dame Press.

MacIntyre, A. (1998). Challenging contemporary politics. In K. Knight (Ed.), The MacIntyre Reader (pp. 223-235). Notre Dame, Indiana: University of Notre Dame Press.

McLellan, H. "Introduction to corporate storytelling". [Online] Available: www. techhead. com/cstory1.htm [cited 14 July 2003], 2002. 
Moran, L. PhD., (2005) . Strategic Reinforcement: The value of making change stick. AchieveGlobal, Inc. archives, April 2005, pg.4

Pearce, W. B. (1989). Communication and the human condition. Southern Illinois University Press.

Pearce, W. B. (2004). The coordinated management of meaning. In W. Gudykunst (Ed.), Theorizing Communication and Culture (pp. 35-54). Thousand Oaks, CA: Sage.

Pearce, W. B. (2007). Making social worlds: A communication perspective. Blackwell Publishing.

Pearce, W. B., \& Littlejohn, S. W. (n.d.). Moral conflicts: when social worlds collide. Thousand Oaks, CA: Sage.

Reamy, T. "Imparting knowledge through storytelling”.KM World, vol. 11, no. 7, [Online] Available:www.kmworld.com [cited 14 July 2003]. 2002.

Rose-Ackerman, S. (2010, November 9). Corruption: Greed, culture, and the state. Retrieved from The Yale Law Journal Online: http://yalelawjournal.org/the-yalelaw-journal-pocket-part/international-law/corruption:-greed,-culture,-and-thestate/

Senge, P. (1990). The fifth discipline: The art and practice of the learning organization. New York, New York: Doubleday.

Solomon, C. M. (1996). Put your ethics to a global test. Personnel Journal, 75(1).

Transparency International. (n.d.). FAQs on corruption. Retrieved from Transparency International Web site: http://www.transparency.org/whoweare/organisation/ faqs_on_corruption

U.S. Securities and Exchange Commission. (2008, December 15). SEC charges Siemens AG for engaging in worldwide bribery. Retrieved from U.S. Securities and Exchange Commission Website: http://www.sec.gov/news/press/2008/2008-294.htm

Wenger, E. "Communities of Practice: the structure of knowledge stewarding". In C. Despres and D. Chauvel (editors), Knowledge horizons: the present and the promise of knowledge management, pp. 205-224 Butterworth Heinemann, Boston, 2000.

Yang, C. F. (1988). Familialism and development: An examination of the role of family in contemporary China mainland, Hong Kong, and Taiwan. In D. Sinha \& H. S. R. Kao (Eds). Social values and development: Asian perspectives, 93-123.

Zalta, E. N. (Ed.). (2008, December 9). Moral relativism. Retrieved from Stanford Encyclopedia of Philosophy: http://plato.stanford.edu/entries/moral-relativism/

Zhang, Zigang (2004, January 1). "Cross-cultural challenges when doing business in China. Singapore Management Review, pg. 54. 